\title{
Laconicum Europae speculum - Lakonsko ogledalo Evrope
}

\section{Prevedel Izidor Janžekovič}

V prvi polovici 18. stoletja je bila objavljena serija devetih oziroma desetih latinskih tiskov $\mathrm{z}$ naslovom Lakonsko ogledalo Evrope (Laconicum Europae speculum). Podobe z napisi je zasnoval Paul Decker mlajši (1685-1742), Johann Wolfgang Baumgartner (17091761) je postavil le tisk za Nizozemca, same bakroreze so izdelali različni bakrorezci (Christian Friedrich Lottes, Johann Georg Pinz, Philipp Andreas Kilian, Andreas Hoffer), uredil in izdal pa jih je Martin Engelbrecht (1684-1756) v Augsburgu okrog leta 1730. Celotni naslov je daljši, Lakonsko ogledalo Evrope, v katerem je brez predsodkov, posmehovanja ali zaničevanja predstavljenih njenih devet posebej uglednih narodov in ljudstev, ki se $v$ določenih lastnostih in znamenjih razlikujejo, vse zaradi radovednosti in zabave (Laconicum Europae speculum: quo Ix. illius praecipuae nationes et populi, absque omni praeiudicio, ludibrio et opprobrio, saltem curiositatis et oblectationis gratia, certis characteribus et symbolis discernuntur, ob oculos positum). ${ }^{1} \mathrm{~V}$ naslovu je torej pojasnjen tudi razlog za nastanek teh tiskov, izšli so "zaradi radovednosti in zabave« (curiositatis et oblectationis gratia). Podobno kot ostale razpredelnice ljudstev ti

1 Engelbrecht, Laconicum Europae speculum. Pri prevodu sem si pomagal s številnimi latinskimi slovarji in glosarji. Ključen za razumevanje besedila je za srednjeveško in zgodnjenovoveško latinščino Du Cange, Glossarium mediae et infimae Latinitatis. Koristna sta bila tudi Niermeyer, Mediae Latinitatis lexicon minus, in Bartal, Glossarium mediae et infimae Latinitatis regni Hungariae. Pri prevajanju v slovenščino mi je pomagal Wiesthaler, Latinsko-slovenski slovar. Za pregled prevoda in številne rešitve mojih nerodnosti se zahvaljujem Martinu Benediku, za pomoč pri določenih izrazih in prevodih še Davidu Movrinu, naposled pa tudi Anji Božič za skrben pregled in številne predloge za izboljšavo. Za vse morebitne nejasnosti in napake sem odgovoren sam. 
bakrorezi niso bili mišljeni kot predstavitev realnih podob, temveč so bili namenjeni tudi zabavi. ${ }^{2}$

Najbolj znana razpredelnica ljudstev je sicer oljna slika anonimnega slikarja s Štajerske iz 18. stoletja, t.i. štajerska Völkertafel (slika 1), zgodovinski vir par excellence za zgodnjenovoveške etnične stereotipe v Evropi. Temeljila je na praktično enakem bakrorezu Josepha Friedricha Leopolda (Leopold-Stich), ki je prav tako kot Lakonsko ogledalo Evrope nastal v Augsburgu v začetka 18. stoletja. Obe različici, Leopoldov bakrorez in štajerska Völkertafel, sta praktično enaki sliki $\mathrm{z}$ manjšimi razlikami, napisani $\mathrm{v}$ različnih narečjih. ${ }^{3}$ Razpredelnica ljudstev predstavi sedemnajst stereotipov ali značilnosti za deset narodov: vedenje, značilnost in značaj, razum, fiziognomijo, znanje, hibe, bolezni, bogočastje, podnebje, temperament itd. Čeprav so bili opisi skopi, so bili prežeti z močno sporočilnostjo. Evropski narodi so razporejeni na osi, ki poteka od zahoda proti vzhodu, od Španca do Turka ali Grka.

Tiski še nikoli niso bili prevedeni v slovenščino in besedilo je kljub majhnemu obsegu nekoliko zahtevno. Glede na razporeditev na štajerski razpredelnici narodov sem tudi Lakonsko ogledalo Evrope razdelil od Španca do Grka. V nasprotju s štajersko razpredelnico ljudstev pri izvirnih Engelbrechtovih podobah iz okrog leta 1730 sicer ni upodobitve za Turka ali Grka. Namesto tega je bil upodobljen Nizozemec (Batavus), čeprav pri tem niso bile naštete vse značilnosti. Zanimiva je izključitev Turkov s seznama »devet posebej uglednih narodov in ljudstev« v Evropi. Morda so bili za Engelbrechta v Augsburgu Turki že oddaljeni - ali pa je povezoval »ugled «s krščanstvom in Turke izključil.

Izhodišče za prevod je sicer tiskana verzija iz leta 1767 , kjer je namesto Nizozemca dodan prav Grk, besedilo pa od tistega na upodobitvah odstopa v zelo redkih nepomembnih podrobnostih. Avtor je $z$ »Grkom« imel v mislih evropska oziroma balkanska ljudstva, ki so živela v otomanskem cesarstvu. To mešanje pripadnosti »narodu « in »državi« je za zgodnji novi vek precej tipično, kar potrjujejo tudi

To Lakonsko ogledalo Evrope je v 18. stoletju izšlo v različnih oblikah in prevodih; prim. Weitenauer, Compendium scientiarum et eruditionis omnigenae, 230-43. Podobe so nastale tudi v španščini, hrani jih ekvadorski narodni muzej v Quitu (Casa de la Cultura). Med drugim so jih namestili tudi na pregradno ali špansko steno oziroma paravan, ki ga hrani muzej Franza Mayerja v Ciudad de Méxicu; Kubiak, »Obraz Innego«, 311-32.

3 Stanzel, Europäer - ein imagologischer Essay; Stanzel, Europäischer Völkerspiegel. 
zgodnejša besedila. Herberstein se recimo v Moskovskih zapiskih Turkov ne loti posebej podrobno, a zapiše, da »evropski Turki, ki govore slovanski jezik, imenujejo Konstantinopel Carigrad, to je kraljevsko mesto. « Tako so očitno podložniki v jugovzhodni Evropi, ki so prišli pod otomansko cesarstvo, obveljali za »evropske Turke«.

V prevodu sem ohranil izvirnikovo kolektivno ednino. Danes je sicer ta raba opešala, a je bila nedavno še precej pogosta. Tako recimo Fran Milčinski (1867-1932) v Butalcih zapiše: »To je bilo tiste dni, ko je Turek, krivoverna ta nesnaga, strašil po deželi in robil živino in mladino. $~^{5}$ Avtor je bil sicer sam relativno nedosleden. Tako recimo pogosto preskakuje med ednino in množino. Različna ljudstva so vedno navedena $\mathrm{v}$ ednini, različne značilnosti oziroma stereotipi pa v ednini ali v množini. Pri prevajanju sem sicer precej zvesto sledil latinskemu izvirniku in ohranil avtorjevo nedoslednost, le pri redkih izjemah sem prevod priredil zaradi lažje razumljivosti v slovenščini.

Večina značilnosti ali stereotipov v Lakonskem ogledalu Evrope je enaka kot pri štajerski Völkertafel, pri čemer se je avtor gotovo naslonil na predhodno upodobitev, se pravi predvsem na Leopoldov bakrorez, ki je prav tako nastal v Augsburgu. Pridevniki se namreč pojavljajo $\mathrm{v}$ primerniku in presežniku, čeprav naj bi vsak tisk stal zase. Toda poleg sedemnajstih stereotipov je Lakonsko ogledalo Evrope dodalo še dodatnih devet značilnosti: temperament, podnebje in zrak, nebesno znamenje, pijačo in hrano, moč (samo za Nizozemca), sposobnost za posel, umetnost in opravila, odnos do žensk, njihovo etnogenezo ter želje za skupno dobro. Posamezni narodi so bili upodobljeni kot večfiguralna alegorična kompozicija na dvoru in s petindvajsetimi značilnostmi ali stereotipi v baročnih kartušah, ki obkrožajo to kompozicijo (slika 2). ${ }^{6}$ Značilnosti so precej naključno razvrščene okrog podob in so pri vsakem narodu drugje, a so v prevodu razvrščene $\mathrm{v}$ enakem vrstnem redu, kot se pojavljajo na štajerski razpredelnici narodov, da je primerjava stereotipov lažja.

4 Herberstein, Moskovski zapiski, 26.

5 Milčinski, Butalci, 12.

6 Engelbrecht, Laconicum Europae speculum. 
Siurze

हैelfinnibung

der

In

हु

Curopa

3refinffichen

dölckern

Und Jifyen

Sligenlchaft fen.
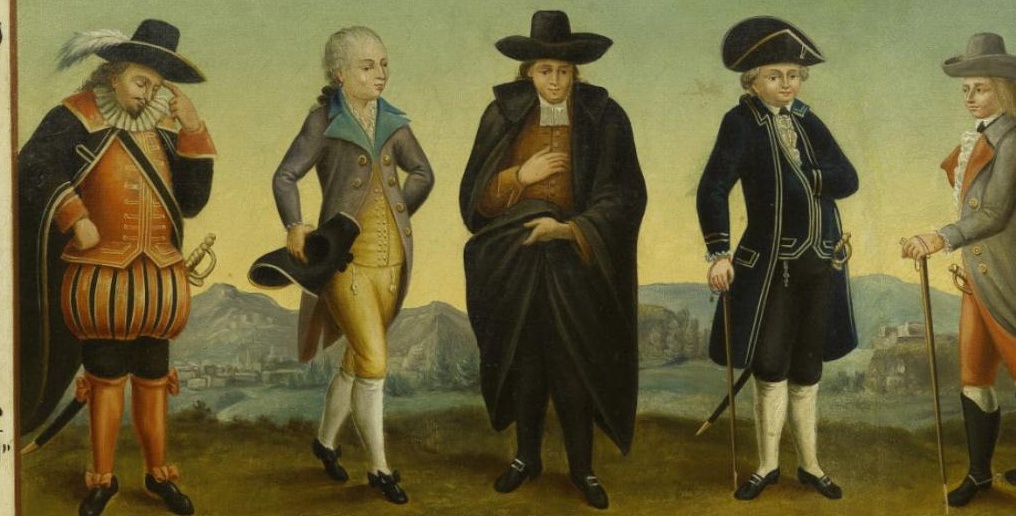

\begin{tabular}{|c|c|c|c|c|c|}
\hline Pramen, & Spanier. & Sranticop. & Sogalich. & Iseutcher. & \\
\hline Siffen & Soofimiffig, & Seinflfining. & inderfiallig. & Iftenfierzig. & \\
\hline 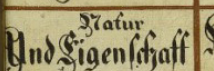 & & $\mathrm{uln}_{\mathrm{n}}$ & ig. & Yanz & \\
\hline SYerffand & Silug un? & 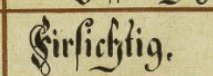 & nig. & गु & \\
\hline 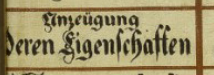 & ánlidś & $\ln 3$ & Wie iederwill, & yber 2ullitit & \\
\hline 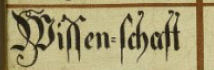 & Forifitige & 3nghive & 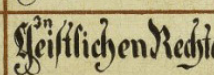 & 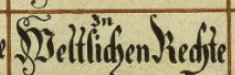 & \\
\hline 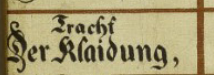 & (8) & $33^{2} b^{2}$ & $\operatorname{sibr} \Gamma_{\mathrm{fam}}$ & & \\
\hline Infugent, & Gothintig, & Befrui & gyeif & 3inford & \\
\hline Siefern. & & & & & \\
\hline anthpeiten. & 23 erfitor & 2 & On böñer feuidg. & Sinkodogrä & \\
\hline $6 r$ ¿and. & $9 \sqrt[3 f]{f n}$ & MSoblgearbitfy & 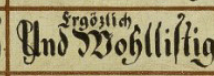 & & \\
\hline rigs İugente & ig, & $\sqrt[9]{\mathrm{rg}}$ & Sirfi & & \\
\hline $\operatorname{Sien} n \hat{\mathrm{t}}$ & itte, & 9 & & 5rod & \\
\hline & & & Sinem & & \\
\hline Uliberfitus & & & $\ln 2$ Szein, & & \\
\hline 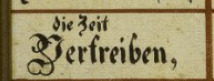 & Wit \$pillen, & Sgit betrügen & 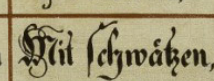 & Plit Zrinden, & \\
\hline 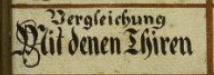 & Gin 2 ilofantfgen & $\sin \xi_{1}$ & Sinnen Sundysen. & Sinen \&öben & \\
\hline Beben inde & in 3oth. & Sin Sirieg, & If Siln Silofiter, & Sin. Wyein, & \\
\hline
\end{tabular}





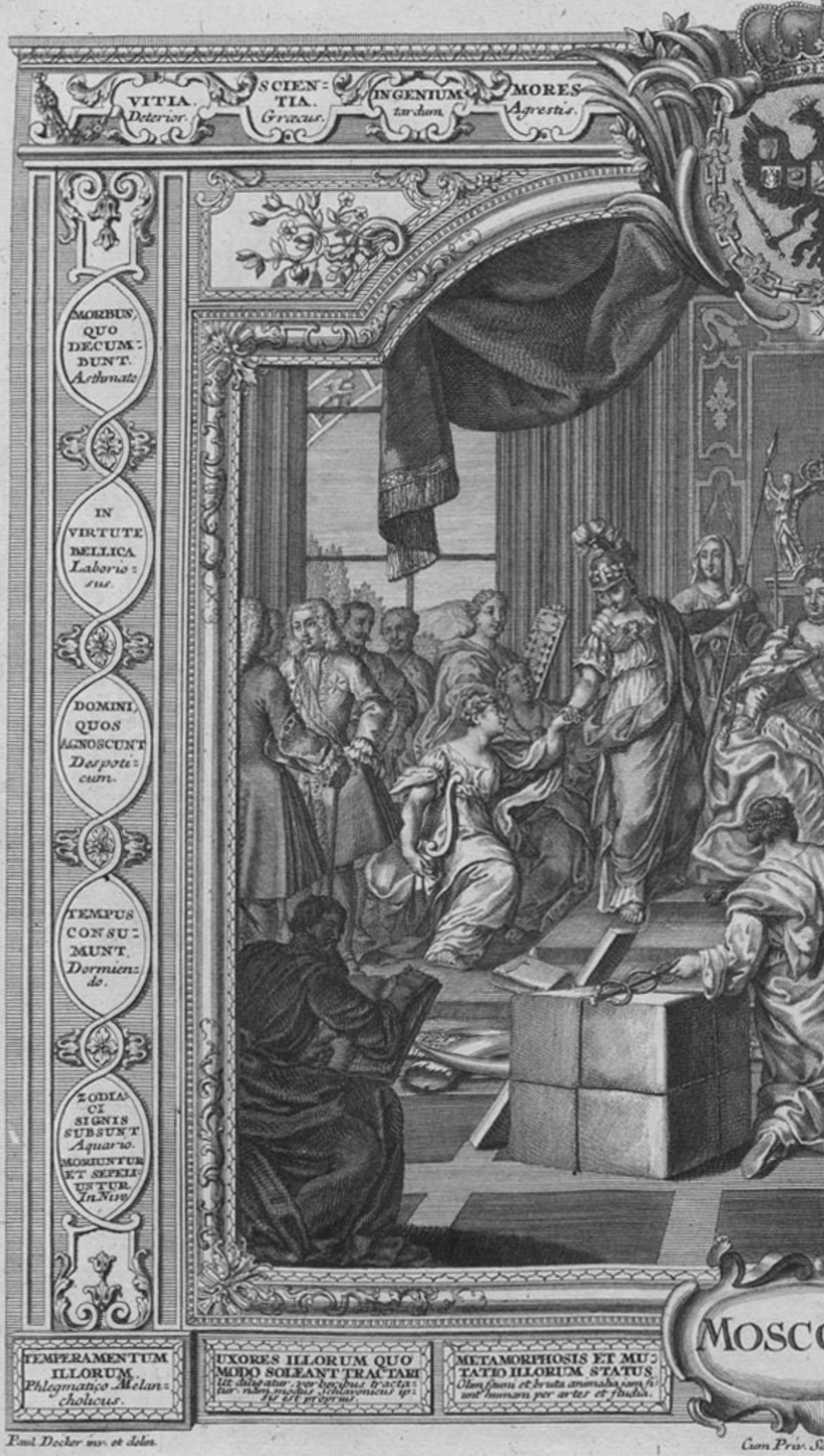




\section{BIBLIOGRAFIJA}

Bartal, Antonius. Glossarium mediae et infimae Latinitatis regni Hungariae. Leipzig: B.G. Teubner, 1901.

Du Cange, Charles du Fresne et al. Glossarium mediae et infimae Latinitatis, $10 \mathrm{zv}$. Niort: L. Favre, 1883-1887.

Engelbrecht, Martin (urednik in založnik). Laconicum Europae speculum. Augsburg, 1730.

Herberstein, Sigismund. Moskovski zapiski. Ljubljana: Slovenska matica, 2001.

Kubiak, Ewa. »Obraz Innego - przedstawienie Królestwa Polskiego z Museo Casa de la Cultura w Quito. "V: Vom »Troglodytenland « ins Reich der Scheherazade: Archäologie, Kunst und Religion zwischen Okzident und Orient; Festschrift für Piotr O. Schplz zum 7o. Geburstag, ur. Magdalena Długosz. Berlin: Frank \& Timme, 2014, 311-32.

Milčinski, Fran. Butalci. Ljubljana: Založba Karantanija, 1999.

Stanzel, Franz K. Europäer - ein imagologischer Essay, 2. izd. Heidelberg: Carl Winter, 1998.

Stanzel, Franz K. (ur.). Europäischer Völkerspiegel: Imagologisch-ethnographische Studien zu den Völkertafeln des frühen 18. Jahrhunderts. Heidelberg: Carl Winter, 1999.

Steirische Völkertafel. Volkskundemuseum Wien, dostopno na spletu. Weitenauer, Felix Anton von. Compendium scientiarum et eruditionis omnigenae: sive tabulae variis ss. patrum, theologorum, ac ascetarum doctrinis efformatae, ut moveant: Exquisitis iuristarum, medicorum, philosophorum, philologorum, et historicorum sententiis, ac aphorismis adornatae, ut doceant; Praeclaris mathematicorum, ethicorum, et politicorum problematibus, proverbiis, et observationibus illustratae, ut delectent. Augsburg: Wagner, 1767.

Wiesthaler, Fran. Veliki latinsko-slovenski slovar. Ljubljana: Kres, 1993-2007. 
Laconicum Europae speculum:

quo Ix. illius praecipuae nationes et populi, absque omni praeiudicio, ludibrio et opprobrio, saltem curiositatis et oblectationis gratia, certis characteribus et symbolis discernuntur, ob oculos positum

Lakonsko ogledalo Evrope,

v katerem je brez predsodkov, posmehovanja ali zaničevanja predstavljenih njenih devet posebej uglednih narodov in ljudstev, ki se v določenih lastnostih in znamenjih razlikujejo, vse zaradi radovednosti in zabave 
MORES

Hispanus Gravis.

Gallus Levis.

Italus Tectus.

Germanus Apertus.

Anglus Pulcher.

Suecus Asper.

Polonus Durus.

Hungarus Crudus.

Moscowita Agrestis.

Graecus Protheus.

GENIUS ET NATURA

Hispanus Mirabilis.

Gallus Affabilis.

Italus Zelotypus.

Germanus Optimus.

Anglus Amabilis.

Suecus Terribilis.

Polonus Terribilior.

Hungarus Terribilissimus.

Moscowita Simillimus.

Graecus Mendacissimus.

INGENIUM

Hispanus Sapiens.

Gallus Prudens.

Italus Perspicax.

Germanus Sagax.

Anglus Solidum.

Suecus Firmum.

Polonus Arduum.

Hungarus Strenuum.

Moscowita Tardum.

Graecus Maximum. 
PO VEDENJU

Španec Resen.

Francoz Lahkomiseln.

Italijan Skrivnosten.

Nemec Odkritosrčen.

Anglež Prijeten.

Šved Osoren.

Poljak Naporen.

Madžar Okruten.

Rus Kmečki.

Grk Nestanoviten.

PO ZNAČILNOSTI IN ZNAČAJU

Španec Krasen.

Francoz Zgovoren.

Italijan Ljubosumen.

Nemec Optimalen.

Anglež Prisrčen.

Šved Strašen.

Poljak Strašnejši.

Madžar Najstrašnejši.

Rus Nadvse podoben.

Grk Skrajno manipulativen.

PO RAZUMU

Španec Pameten.

Francoz Preudaren.

Italijan Ostroumen.

Nemec Bistroumen.

Anglež Neomajen.

Šved Vztrajen.

Poljak Naporen.

Madžar Živahen.

Rus Počasen.

Grk Izreden. 
PHYSIOGNOMIA

Hispanus Virilis.

Gallus Puerilis.

Italus Generis communis.

Germanus Generis omnis.

Anglus Generis feminini.

Suecus Taetricus.

Polonus Rotundus.

Hungarus Truculentus.

Moscowita Incultus.

Graecus Delicatus.

SCIENTIA

Hispanus Theologus.

Gallus Polemicus.

Italus Canonista.

Germanus Iurista.

Anglus Philosophus.

Suecus Philologus.

Polonus Linguista.

Hungarus Latinus.

Moscowita Graecus.

Graecus Pseudo-politicus.

VESTITUS

Hispanus Modestus.

Gallus Protheus.

Italus Honestus.

Germanus Simius.

Anglus Gallus.

Suecus Coriaceus.

Polonus Togatus.

Hungarus Coloratus.

Moscowita Pelliceus.

Graecus Femineus. 
PO FIZIOGNOMIJI

$\begin{array}{ll}\text { Španec } & \text { Možat. } \\ \text { Francoz } & \text { Deški. } \\ \text { Italijan } & \text { Običajen. } \\ \text { Nemec } & \text { Raznovrsten. } \\ \text { Anglež } & \text { Poženščen. } \\ \text { Šved } & \text { Resnoben. } \\ \text { Poljak } & \text { Zaobljen. } \\ \text { Madžar } & \text { Robusten. } \\ \text { Rus } & \text { Zanemarjen. } \\ \text { Grk } & \text { Delikaten. }\end{array}$

PO ZNANJU

Španec Teolog.

Francoz Polemik.

Italijan Kanonist.

Nemec Jurist.

Anglež Filozof.

Šved Filolog.

Poljak Lingvist.

Madžar Latinec.

Rus Grk.

Grk Psevdo-politik.

OBLAČI SE

Španec Skromno.

Francoz Raznovrstno.

Italijan Dostojno.

Nemec Opičje.

Anglež Francosko.

Šved V usnje.

Poljak Gosposko.

Madžar Raznobarvno.

Rus V krzno.

Grk Poženščeno. 
VITIA

Hispanus Superbus.

Gallus Fraudulentus.

Italus Luxuriosus.

Germanus Prodigus.

Anglus Turbulentus.

Suecus Superstitiosus.

Polonus Ostentator.

Hungarus Inconstans.

Moscowita Deterior.

Graecus Fallacior.

AMANT

Hispanus Gloriam.

Gallus Militiam.

Italus Aurum.

Germanus Potum.

Anglus Delicias.

Suecus Escas.

Polonus Nobilitatem.

Hungarus Rebellionem.

Moscowita Fustem.

Graecus Philautiam.

MORBUS, QUO DECUMBUNT

Hispanus Hypocondriaco.

Gallus Suo.

Italus Peste.

Germanus Pede.

Anglus Tabe.

Suecus Hydrope.

Polonus Plica.

Hungarus Phrenetico.

Moscowita Asthmate.

Graecus Debilitate. 
PO HIBAH

$\begin{array}{ll}\text { Španec } & \text { Ošaben. } \\ \text { Francoz } & \text { Goljufiv. } \\ \text { Italijan } & \text { Razvraten. } \\ \text { Nemec } & \text { Zapravljiv. } \\ \text { Anglež } & \text { Nemiren. } \\ \text { Šved } & \text { Vraževeren. } \\ \text { Poljak } & \text { Našopirjen. } \\ \text { Madžar } & \text { Nestanoviten. } \\ \text { Rus } & \text { Nizkoten. } \\ \text { Grk } & \text { Prevarantski. }\end{array}$

LJUBIJO

Španec Slavo.

Francoz Vojaštvo.

Italijan Zlato.

Nemec Pijačo.

Anglež Naslado.

Šved Jedačo.

Poljak Plemstvo.

Madžar Vstajo.

Rus Palico.

Grk Sam sebe.

BOLEZEN, ZA KATERO UMRO

Španec Hipohondrija.

Francoz Njegova (= sifilis).

Italijan Kuga.

Nemec Putika.

Anglež Jetika.

Šved Vodenica.

Poljak Pletenica.

Madžar Norost.

Rus Naduha.

Grk Oslabelost. 
TERRA, QUAM INHABITANT

Hispanus Fecundam.

Gallus Excultam.

Italus Delicatam.

Germanus Bonam.

Anglus Humidam.

Suecus Montosam.

Polonus Silvestrem.

Hungarus Praedivitem.

Moscowita Glacialem.

Graecus Dulciorem.

IN VIRTUTE BELLICA

Hispanus Magnanimus.

Gallus Astutus.

Italus Providus.

Germanus Invictus.

Anglus Archithalassus.

Suecus Infractus.

Polonus Impetuosus.

Hungarus Turbulentus.

Moscowita Laboriosus.

Graecus Pigerrimus.

IN CULTU RELIGIONIS

Hispanus Optimus.

Gallus Bonus.

Italus Melior.

Germanus Devotior.

Anglus Minus constans.

Suecus Simplicissimus.

Polonus Multiplex.

Hungarus Indiscretus.

Moscowita Superstitiosus.

Graecus Simillimus. 
DEŽELA, KJER ŽIVIJO

$\begin{array}{ll}\text { Španec } & \text { Rodovitna. } \\ \text { Francoz } & \text { Lepo obdelana. } \\ \text { Italijan } & \text { Krasna. } \\ \text { Nemec } & \text { Dobra. } \\ \text { Anglež } & \text { Vlažna. } \\ \text { Šved } & \text { Hribovita. } \\ \text { Poljak } & \text { Gozdnata. } \\ \text { Madžar } & \text { Bogata. } \\ \text { Rus } & \text { Ledena. } \\ \text { Grk } & \text { Očarljiva. }\end{array}$

PO VOJAŠKI VEŠČINI

Španec Pogumen.

Francoz Prebrisan.

Italijan Previden.

Nemec Nepremagljiv.

Anglež Prvi na morju.

Šved Zlomljen.

Poljak Napadalen.

Madžar Prevratniški.

Rus Težaven.

Grk Skrajnolen.

V BOGOČASTJU

Španec Najboljši.

Francoz Dober.

Italijan Boljši.

Nemec Pobožnejši.

Anglež Bolj nestalen.

Šved Skrajno preprost.

Poljak Raznovrsten.

Madžar Neizbirčen.

Rus Vraževeren.

Grk Zelo podoben. 
DOMINI, QUOS AGNOSCUNT

Hispanus Monarcham.

Gallus Regem.

Italus Patriarcham.

Germanus Augustum.

Anglus Mixtum.

Suecus Dominum.

Polonus Electum.

Hungarus Invitum.

Moscowita Despoticum.

Graecus Tyrannum.

ABUNDANT

Hispanus Fructibus.

Gallus Mercibus.

Italus Vino.

Germanus Frumento.

Anglus Pascuis.

Suecus Metallis.

Polonus Pellibus.

Hungarus Omnibus.

Moscowita Apibus.

Graecus Mollibus.

TEMPUS CONSUMUNT

Hispanus Ludendo.

Gallus Fallendo.

Italus Loquendo.

Germanus Bibendo.

Anglus Laborando.

Suecus Comedendo.

Polonus Rixando.

Hungarus Otiando.

Moscowita Dormiendo.

Graecus Aegrotando. 
ZA VLADARJA PRIZNAVAJO

$\begin{array}{ll}\text { Španec } & \text { Monarha. } \\ \text { Francoz } & \text { Kralja. } \\ \text { Italijan } & \text { Patriarha. } \\ \text { Nemec } & \text { Cesarja. } \\ \text { Anglež } & \text { Različne. } \\ \text { Šved } & \text { Gospoda. } \\ \text { Poljak } & \text { Izvoljenega. } \\ \text { Madžar } & \text { Neželenega. } \\ \text { Rus } & \text { Despota. } \\ \text { Grk } & \text { Tirana. }\end{array}$

IMAJO OBILICO

$\begin{array}{ll}\text { Španec } & \text { Pridelkov. } \\ \text { Francoz } & \text { Dobrin. } \\ \text { Italijan } & \text { Vina. } \\ \text { Nemec } & \text { Žita. } \\ \text { Anglež } & \text { Pašnikov. } \\ \text { Šved } & \text { Rudnikov. } \\ \text { Poljak } & \text { Krzna. } \\ \text { Madžar } & \text { Vsega. } \\ \text { Rus } & \text { Čebel. } \\ \text { Grk } & \text { Mehkužnežev. }\end{array}$

ČAS PREŽIVLJAJO

Španec Z igrami.

Francoz Z goljufanjem.

Italijan S klepetanjem.

Nemec S popivanjem.

Anglež Z delom.

Šved S prehranjevanjem.

Poljak S pričkanjem.

Madžar Z Z brezdeljem.

Rus S spanjem.

Grk Z bolehanjem. 
ANIMALIA, QUIBUS COMPARANDUS

Hispanus Elephas.

Gallus Vulpes.

Italus Lynx.

Germanus Leo.

Anglus Equus.

Suecus Taurus.

Polonus Ursus.

Hungarus Lupus.

Moscowita Alces.

Graecus Elurus.

MORIUNTUR ET SEPELIUNTUR

Hispanus In lecto.

Gallus In bello.

Italus In terrae motu.

Germanus In potu.

Anglus In aqua.

Suecus In terra.

Polonus In stabulo.

Hungarus Acinace.

Moscowita In nive.

Graecus In fraude.

TEMPERAMENTUM ILLORUM

Hispanus Melancholicus.

Gallus Sanguineus.

Italus Cholericus.

Germanus Phlegmaticus.

Anglus Sanguineo-cholericus.

Suecus Melancholico-sanguineus.

Polonus Cholerico-phlegmaticus.

Hungarus Cholerico-sanguineus.

Moscowita Phlegmatico-melancholicus.

Graecus Melancholico-cholericus. 
ŽIVALI, S KATERIMI JIH GRE PRIMERJATI

$\begin{array}{ll}\text { Španec } & \text { Slon. } \\ \text { Francoz } & \text { Lisica. } \\ \text { Italijan } & \text { Ris. } \\ \text { Nemec } & \text { Lev. } \\ \text { Anglež } & \text { Konj. } \\ \text { Šved } & \text { Bik. } \\ \text { Poljak } & \text { Medved. } \\ \text { Madžar } & \text { Volk. } \\ \text { Rus } & \text { Los. } \\ \text { Grk } & \text { Mačka. }\end{array}$

UMRO IN SO POKOPANI

$\begin{array}{ll}\text { Španec } & \text { V postelji. } \\ \text { Francoz } & \text { V vojni. } \\ \text { Italijan } & \text { V potresu. } \\ \text { Nemec } & \text { V pijači. } \\ \text { Anglež } & \text { V vodi. } \\ \text { Šved } & \text { V zemlji. } \\ \text { Poljak } & \text { V hlevu. } \\ \text { Madžar } & \text { Pod sabljo. } \\ \text { Rus } & \text { V snegu. } \\ \text { Grk } & \text { V prevari. }\end{array}$

NJIHOV TEMPERAMENT

Španec Melanholik.

Francoz Sangvinik.

Italijan Kolerik.

Nemec Flegmatik.

Anglež Sangvineo-kolerik.

Šved Melanholiko-sangvinik.

Poljak Koleriko-flegmatik.

Madžar Koleriko-sangvinik.

Rus Flegmatiko-melanholik.

Grk Melanholiko-kolerik. 
CLIMA POLI ET AERIS

Hispanus Siccum, sed valde bonum.

Gallus Temperatum et iucundum.

Italus Calidum, sed humido mixtum.

Germanus Varium, sed ubique sanum.

Anglus Nebulosum, sed fecundum.

Suecus Austerum, sed innoxium.

Polonus Frigidum, sed frugiferum.

Hungarus Bonum et sponte benignum.

Moscowita Nivosum et miserum.

Graecus Optimum et neglectum.

ZODIACI SIGNIS SUBSUNT

$\begin{array}{ll}\text { Hispanus } & \text { Cancro. } \\ \text { Gallus } & \text { Geminis. } \\ \text { Italus } & \text { Librae. } \\ \text { Germanus } & \text { Virgini. } \\ \text { Anglus } & \text { Arieti. } \\ \text { Suecus } & \text { Piscibus. } \\ \text { Polonus } & \text { Capricorno. } \\ \text { Hungarus } & \text { Sagittario. } \\ \text { Moscowita } & \text { Aquario. } \\ \text { Graecus } & \text { Scorpio. }\end{array}$

IN POTU ET CIBO

Hispanus Parcus et sobrius.

Gallus Bonus et optime paratus.

Italus Temperatus et frugalis.

Germanus Multus et exquisitus.

Anglus Lautus et conditus.

Suecus Durus et simplex.

Polonus Sumptuosus et opiparus.

Hungarus Copiosus et prodigus.

Moscowita Miserrimus, sed assuetus.

Graecus Delicatus et generosus. 
PODNEBJE IN OZRAČJE

Španec Suho, a zelo dobro.

Francoz Zmerno in prijetno.

Italijan Toplo, a pomešano $\mathrm{z}$ vlago.

Nemec Raznovrstno, a povsod blagodejno.

Anglež Oblačno, a rodovitno.

Šved Ostro, a neškodljivo.

Poljak Hladno, a rodovitno.

Madžar Dobro in samo po sebi ugodno.

Rus Zasneženo in bedno.

Grk Najboljše in neizkoriščeno.

NEBESNO ZNAMENJE, POD KATERIM ŽIVIJO

Španec Rak.

Francoz Dvojčka.

Italijan Tehtnica.

Nemec Devica.

Anglež Oven.

Šved Ribi.

Poljak Kozorog.

Madžar Strelec.

Rus Vodnar.

Grk Škorpijon.

PIJAČA IN HRANA

Španec Skopa in trezna.

Francoz Dobra in odlično pripravljena.

Italijan Zmerna in skromna.

Nemec Obilna in izbrana.

Anglež Razkošna in začinjena.

Šved Surova in preprosta.

Poljak Draga in bogata.

Madžar Obilna in potratna.

Rus Skrajno bedna, a v navadi.

Grk Slastna in odlična. 
Hispanus Ad speculationes rerum sublimium, metaphysica tiones ipsorum entium, et partum montium; in risum omnium.

Gallus Ad negotiationes, ad legationes et fascinationes. Plusquam viri in primo impetu, plusquam feminae in malo exitu.

Italus In choro et foro ad novem musas, Apollini charas, et ubi boni nulli meliores, ubi mali nulli peiores.

Germanus In sago et toga ut olim barbari, iam vere incliti, invicti milites, summi artifices et rerum caesares.

Anglus Ad artem nauticam et omnem scientiam per totum mundum iam famosissimam.

Suecus Ad laboriosa et periculosa ut veri filii Martis et Palladis.

Polonus Ad artem mechanicam, ad linguam exteram, si vitent otium aut discordiam.

Hungarus Ad machinationes et invasiones in terras exteras, ad proiciendum corpus et animam.

Moscowita Ad serviendum et obediendum ad principis nutum sive sit aequum, sive iniustum.

Graecus Ad stratagemata, ad problematica, ad studia omnia et haeresis dogmata.

UXORES ILLORUM QUO MODO SOLEANT TRACTARI

Hispanus Bonam amat, multumque honorat; sin secus, negligit, et aliam invenit.

Gallus Dat pulchris nimiam libertatem et gloriam; ex pompa vestium virtutis exitium.

Italus Has quaerit sedule, observat strenue, concludit rigide, ne fiant impiae.

Germanus Sunt eis omnia cum viris communia, quia oeconoma, nec serva nec domina.

Anglus Concedit profanas omnes delicias et iam ipsas plerumque caligas.

Suecus Honeste tractat, rite observat, et strenue imperat.

Polonus Devotam aestimat, modestam adamat, sed mala vapulat, ut se se corrigat. 
SPOSOBNOST ZA POSEL, UMETNOST IN OPRAVILA

Španec Zavznesena umovanja, metafizičarjenja o lastnih bitnostih in tresenju gora;vsakogar tarča posmehovanja.

Francoz Za kupčije, delegacije in sleparije; možati v prvem zaletu, babji ob slabem razpletu.

Italijan $\quad \mathrm{V}$ zboru in na trgu so Apolonu in devetero muzam dragi; kjer so dobri, ni nihče boljši, kjer so slabi, ni nihče slabši.

Nemec Nekoč sloveli so barbari, danes so ugledni v togi in bojni opravi; vojaki brez porazov in izvrstni obrtniki, vseh stvari oblastniki.

Anglež Danes znani po mornarskih spretnostih, vsepovsod slove po raznovrstnih vednostih.

Šved V nevarnosti ali garaštvu kot sinovi Ateni in Marsu.

Poljak Za tuje jezike in tehnične veščine, če le ne zaidejo $\mathrm{v}$ brezdelje in razprtije.

Madžar Za spletke in vpade v tuje dežele, za zanemarjanje dušne in telesne potrebe.

Rus Uslužni in pokorni na vsak mig vladarja, naj bo pošten ali pokvarjen.

Grk Za spletkarjenje in disputacije brez rešitve, za vsakovrstne nauke in heretične doktrine.

Španec Če je dobra, jo ljubi in zelo spoštuje; če ne, si najde drugo in jo pusti ob strani.

Francoz Popustljiv je z lepoticami in jih pretirano slavi razkošje oblačil, čednosti pogin.

Italijan Marljivo išče in jih budno opazuje; v izogib brezbožnosti jih strogo omejuje.

Nemec Ženskam je vse skupno z moškimi; čeprav skrbe za hišo, niso ne služabnice, ne gospodarice.

Anglež Pristane na vse posvetne rádosti; čeprav jih danes največkrat zataji.

Šved Z Z njimi ravna pošteno in kot je običajno; gospoduje - neomajno.

Poljak Če je vdana, jo spoštuje, in dobrosrčno vroče ljubi; da se znebi malopridnosti, pa seže po šibi. 
Hungarus Vult nunquam barbaram, sed semper placidam et sic morigera erit charissima.

Moscowita Ut diligatur, verberibus tractatur, nam modus Schlavonicus ipsis est proprius.

Graecus Ut insolentiam contineat femineam, spiritus refrenat, multum humiliat, exinde adorat.

QUAE AB ISTIS DESIDERANTUR A BONO PUBLICO

Hispanus Maior industria, commercia propria, exteros non spernat, fastum deponat, acquisita non perdat.

Gallus S. Ludovici imitatio, Palaestinae recuperatio, sciant promissum cadere in debitum.

Italus Nomen Sanctissimi magis impleant, leges quas dictitant, non ita negligant, pro re communi potius consulant.

Germanus Principum concordia, religio unica, prisca sinceritas, vitae frugalitas.

Anglus Maior observantia in capita regia, absint dissidia ex haeresi varia.

Suecus Se inter limites contineat, et milites, nam male parta dilabuntur, haeredes regni puniuntur.

Polonus Regni tranquillitas, vitae sobrietas, nervus rerum omnium, bonum est aerarium.

Hungarus Regi sit fidelis, legi non rebellis, universi vincuntur, ubi singuli congrediuntur.

Moscowita Pergat bonis avibus, in addiscendis artibus. Sciat quod sit otium diaboli pulvinarium.

Graecus Sapiat cum Phrygibus, utatur suis dotibus, nam tertius habet praemium, si inter duos proelium. 
Madžar Divjakinje ne mara, všeč mu je blaga narava; bolj kot mu služi, bolj se mu priljubi.

Rus Kot jo obožuje, jo tudi mlati; slovanske šege se je privadil držati.

Grk Da obrzda žensko ošabno samovoljnost, jo veliko ponižuje; ko to doseže, jo poveličuje.

\section{ČESA SI JE OD NJIH ŽELETI ZA SKUPNO DOBRO}

Španec Večja vnema, lastna trgovina, tujcev naj ne zaničuje, naj se znebi praznikov, in $\mathrm{z}$ dobičkom varčuje.

Francoz Svetega Ludvika posnemanje in zavzetje Palestine, zavedanje, da obljuba zapade v dolg.

Italijan Svetemu imenu naj bolj zadostijo, zakone raje upoštevajo, kot o njih le govorijo, za skupno dobro naj bolje skrbijo.

Nemec Sloga med vladarji, verska enotnost, starodavna poštenost in življenjska skromnost.

Anglež Več pokornosti do kronanih glav, manj razprtij zaradi vseh vrst herezij.

Šved Naj se znotraj svojih meja in vojske drži; kar je pridobljeno po krivici, se hitro razprši, kaznovani so kraljestva dediči.

Poljak Mirno kraljestvo in v življenju treznosti, ni boljšega zaklada od obče sile in moči.

Madžar Naj se ne upira zakonu in naj bo kralju zvest, razdeljenost v spopadu - skupen poraz.

Rus Pod znamenji ugodnimi naj nadaljuje ukv umetnosti; naj dobro zna, da je brezdelje leglo vsega zla.

Grk Naj izkoristi svoje danosti in s Frigici po pameti ravna, saj kjer se prepirata dva, tretji dobiček ima. 